\title{
Catalytic Hydrogenation of Thioesters, Thiocarbamates, and Thioamides
}

\author{
Jie Luo, Michael Rauch, Liat Avram, Yehoshoa Ben-David, and David Milstein* \\ Cite This: J. Am. Chem. Soc. 2020, 142, 21628-21633 \\ Read Online
}

ABSTRACT: Direct hydrogenation of thioesters with $\mathrm{H}_{2}$ provides a facile and waste-free method to access alcohols and thiols. However, no report of this reaction is documented, possibly because of the incompatibility of the generated thiol with typical hydrogenation catalysts. Here, we report an efficient and selective hydrogenation of thioesters. The reaction is catalyzed by an acridine-based ruthenium complex without additives. Various thioesters were fully hydrogenated to the corresponding alcohols and thiols with excellent tolerance for amide, ester, and carboxylic acid groups. Thiocarbamates and thioamides also undergo hydrogenation under similar conditions, substantially extending the application of hydrogenation of organosulfur compounds.

$\mathrm{T}$ he four-electron reduction of thioesters by $\mathrm{NAD}(\mathrm{P}) \mathrm{H}$ to thiols and alcohols is well-known as the terminating step of non-ribosomal peptide synthetase and polyketide synthase involved biosynthetic processes. ${ }^{1}$ Due to the mild biological reducing conditions, multifunctionalized natural alcoholic products such as myxochelin A and myxalamid A are directly accessed (Scheme 1a). ${ }^{1 a}$ In contrast, current synthetic methods

Scheme 1. Hydrogenation of Thioesters toward Thiols and Alcohols

a. Natural alcoholic products from biological reduction of thioesters

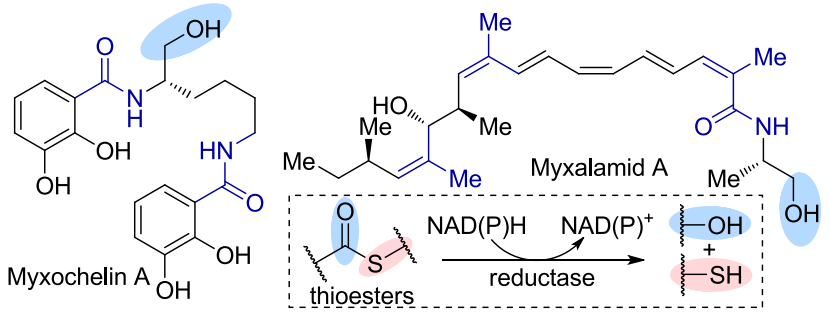

b. This work: Hydrogenation of thioesters towards alcohols and thiols

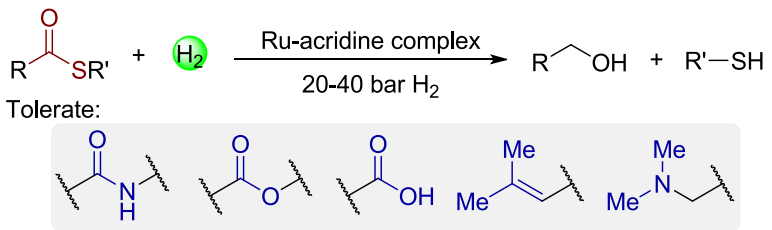

for the reduction of thioesters to alcohols and thiols still largely rely on the use of stoichiometric amounts of hydride reagents, ${ }^{2}$ which not only generate significant waste, but also limit application in synthesis because of possible over-reduction of unsaturated functional groups. Inspired by biological reduction of thioesters and also considering the ubiquity of thioesters in foods, cosmetics, antibiotics, and natural products, ${ }^{3}$ developing a selective and green reducing method for thioesters can access various alcohols and widely used mercaptans ${ }^{4}$.
In the context of producing high-value chemicals from biobased feedstocks through more sustainable methods, hydrogenation of carboxylic acids and their derivatives is of great importance for generating versatile organic building blocks in a waste-free fashion, as compared to traditional reducing methods using hydride reagents. ${ }^{5}$ Recent years have witnessed great progress in this area using $\mathrm{H}_{2}$ in transforming carboxylic acids, ${ }^{6}$ esters, ${ }^{7}$ amides, ${ }^{8}$ and even carbonates, carbamates, and ureas $^{9}$ to a vast number of alcohols and amines. Nonetheless, to the best of our knowledge, the hydrogenation of thioesters is yet to be reported, ${ }^{10}$ possibly due to the generation of thiols which might retard typical metal-catalyzed hydrogenation systems. Here we report our discovery of the hydrogenation of thioesters directly toward thiols and alcohols catalyzed by a Ru-acridine complex. Functional groups including amide, ester, carboxylic acid, and trisubstituted double bonds are tolerated (Scheme 1b). In addition, this system also enables hydrogenation of thiocarbamates and thioamides, demonstrating its efficiency and versatility.

Very recently, our group developed a Ru-acridine complex (Scheme 2a, Ru-1)-catalyzed synthesis of thioesters by dehydrogenative coupling of thiols and alcohols, evolving $\mathrm{H}_{2}$ as the only byproduct. ${ }^{11 a}$ In studying this reaction, a $\mathrm{Ru}-$ thiolate acridine complex (Ru-3) was isolated from the reaction of Ru-1 and hexanethiol, which was also a catalytically active species. Interestingly, Ru-3 was demonstrated to heterolytically split $\mathrm{H}_{2}$ at 1 bar to generate a hydrido-thiol complex (Ru-2) at room temperature. In accordance with the ease of regenerating the hydrido-thiol ruthenium complex, we wondered whether this system can hydrogenate thioesters

Received: October 14, 2020

Published: December 17, 2020 
Scheme 2. Stoichiometric Experiments toward Hydrogenation of Thioesters

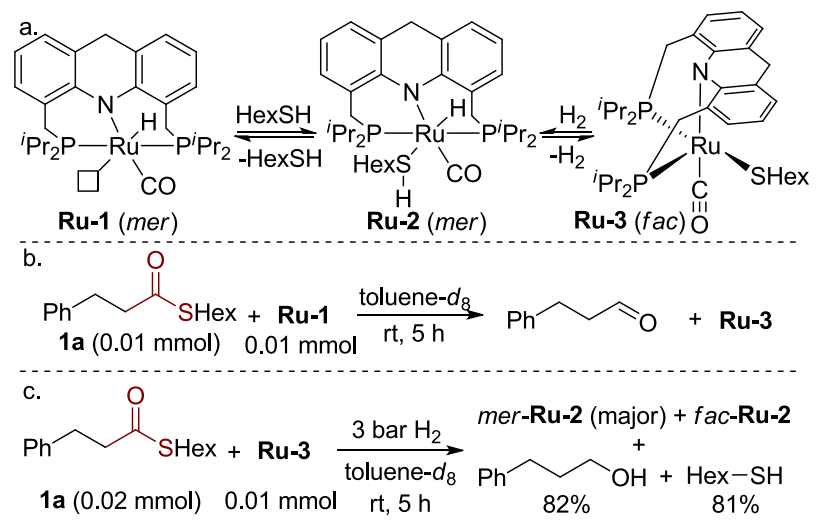

under $\mathrm{H}_{2}$ pressure, despite the accumulation of free thiol during the reaction.

Toward this end, a preliminary stoichiometric experiment was carried out in which equivalent amounts of thioester 1a and Ru-1 were mixed in toluene at room temperature. Interestingly, all of Ru-1 transformed into Ru-3 with the generation of the corresponding aldehyde in a few hours, indicating the capability of $\mathbf{R u} \mathbf{- 1}$ to reduce the thioester (Scheme $2 \mathrm{~b}) .^{12}$ However, in a catalytic reaction in which excess thiol is present, it is important that Ru-3 would still be capable of catalyzing the hydrogenation of thioesters under $\mathrm{H}_{2}$. Therefore, the Ru-thiolate complex (Ru-3) was tested in hydrogenation of 2 equiv of thioester 1 a under 3 bar $\mathrm{H}_{2}$ in toluene at room temperature (Scheme 2c). Encouragingly, after $5 \mathrm{~h}$, nearly no thioester 1a was observed by NMR, and alcohol and thiol were generated, while $\mathbf{R u}-3$ converted to $\mathrm{Ru}$ hydrido-thiol isomers (mer- and fac-Ru-2).

Based on this promising result, catalytic experiments were further explored directly using Ru-1 as the catalyst (Table 1). While low conversion was observed using toluene as solvent (entry 1, 23\%), 50\% of thioester 1a was successfully hydrogenated to the alcohol and hexanethiol in dioxane under 10 bar $\mathrm{H}_{2}$ at room temperature after $36 \mathrm{~h}$ (46\% and 48\% yields, respectively, entry 2 ). However, the conversion was still incomplete even upon prolonging the reaction to 5 days (entry

Table 1. Screening of Catalytic Reactions ${ }^{a}$

\begin{tabular}{|c|c|c|c|c|}
\hline & $1 a$ & $+\mathrm{H}_{2}$ & $\frac{\text { Ru-1 }}{\text { dioxane }}$ & $\underset{\mathbf{3 a}}{\mathrm{O}}$ \\
\hline entry & $T\left({ }^{\circ} \mathrm{C}\right)$ & $\mathrm{H}_{2} \underset{(\text { bar })}{\text { pressure }}$ & $\begin{array}{c}\text { conversion of 1a } \\
(\%)^{b}\end{array}$ & $\begin{array}{c}\text { yields of } 2 \mathrm{a} / 3 \mathrm{a} \\
(\%)^{b}\end{array}$ \\
\hline $1^{c}$ & r.t. & 10 & 23 & $19 / 22$ \\
\hline 2 & r.t. & 10 & 50 & $46 / 48$ \\
\hline $3^{d}$ & r.t. & 10 & 70 & $64 / 68$ \\
\hline $4^{e}$ & r.t. & 10 & 17 & $11 / 14$ \\
\hline $5^{f}$ & r.t. & 10 & 92 & $81 /-$ \\
\hline 6 & r.t. & 40 & 58 & $52 / 56$ \\
\hline 7 & 135 & 20 & $>99$ & $94(92) / 96$ \\
\hline
\end{tabular}

${ }^{a}$ Conditions: 1a $(0.5 \mathrm{mmol})$, catalyst Ru-1 (1.0 mol\%), dioxane (1 $\mathrm{mL}), 36 \mathrm{~h} .{ }^{b}$ Conversions/yields were determined by GC using benzyl benzoate as internal standard; isolated yields in parentheses. ${ }^{c}$ Toluene $(1 \mathrm{~mL})$ as solvent. ${ }^{d} 5$ days. ${ }^{e} \mathrm{HexSH}$ (1 equiv) was added before the reaction. ${ }_{3}$-Phenylpropionaldehyde $(0.5 \mathrm{mmol})$ was used as substrate in the presence of $\mathrm{HexSH}$ (1 equiv); 4\% ester was generated.
3, 70\%). We propose that under these conditions, the thiol can still inhibit the hydrogenation upon accumulation during the reaction. To further verify this point, a control experiment was performed by adding 1 equiv of hexanethiol before the reaction. As expected, only $17 \%$ conversion of the thioester was observed under the same conditions (entry 4). Notably, employing 3-phenylpropionaldehyde as the substrate (instead of thioester 1a) in the presence of 1 equiv of hexanethiol, nearly full conversion of the aldehyde was observed (entry 5). These experiments, taken together (entries 4 and 5), indicate that the presence of thiol slows down only the step of thioester conversion to aldehyde. In addition, in all of the incomplete reactions, only trace aldehyde was detected after the reaction, supporting that the step from aldehyde to alcohol is not ratedetermining.

To promote the reaction, we then evaluated the effect of hydrogen pressure and temperature. Increasing $\mathrm{H}_{2}$ pressure to 40 bar, the conversion was only slightly improved, indicating that $\mathrm{H}_{2}$ pressure is not the key factor of the hydrogenation (Table 1 , entry $6,58 \%$ conversion). Interestingly, heating the reaction to $135{ }^{\circ} \mathrm{C}$ under 20 bar $\mathrm{H}_{2}$ resulted in full conversion of the thioester with no side reactions, affording the alcohol and the thiol in $94 \%$ and $96 \%$ yields, respectively (entry 7 ). In consideration of the former results (entries 2-4), heating appears to facilitate the dissociation of thiol from the ruthenium center (Scheme 3, i), possibly suggesting that Ru-

\section{Scheme 3. Proposed Mechanism}

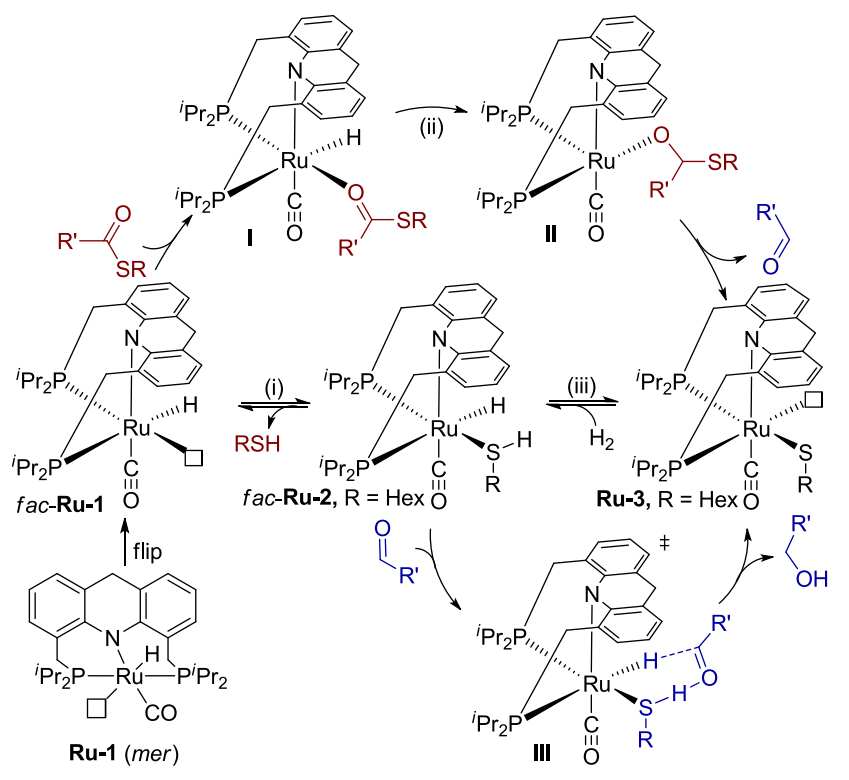

$\mathbf{1}$ is the active species in the initial conversion of the thioester to aldehyde. Prior mechanistic insights on related systems indicate that $\mathbf{R u}-\mathbf{1}$ likely first isomerizes to $f a c-\mathbf{R u}-\mathbf{1}$ with a vacant site cis to the hydride, ${ }^{11 b, c}$ which might facilitate the insertion of the coordinated thioester into the Ru-hydride bond (Scheme 3, ii, I to II). In contrast, based on the result that the presence of thiol does not affect the hydrogenation of aldehyde to alcohol (entry 5), an outer-sphere transition state III $^{11 \mathrm{~b}}$ is proposed for aldehyde hydrogenation, in which $\mathbf{R u}-\mathbf{2}$ is the active species. In the whole pathway, the presence of $\mathrm{H}_{2}$ ensures the regeneration of the $\mathrm{Ru}-\mathrm{H}$ species from $\mathbf{R u}-3$ (Scheme 3, iii), thereby driving the hydrogenation reaction. 
To further prove the high efficiency of the developed system, ${ }^{13}$ a scaled-up reaction was carried out under 30 bar $\mathrm{H}_{2}$ at $150{ }^{\circ} \mathrm{C}$. Notably, $5 \mathrm{mmol}$ thioester $1 \mathrm{a}$ was fully converted to the products with $0.2 \mathrm{~mol} \%$ catalyst in only $2 \mathrm{~h}$ (Scheme 4, 1a,

Scheme 4. Hydrogenation of S-Hexyl Thioesters

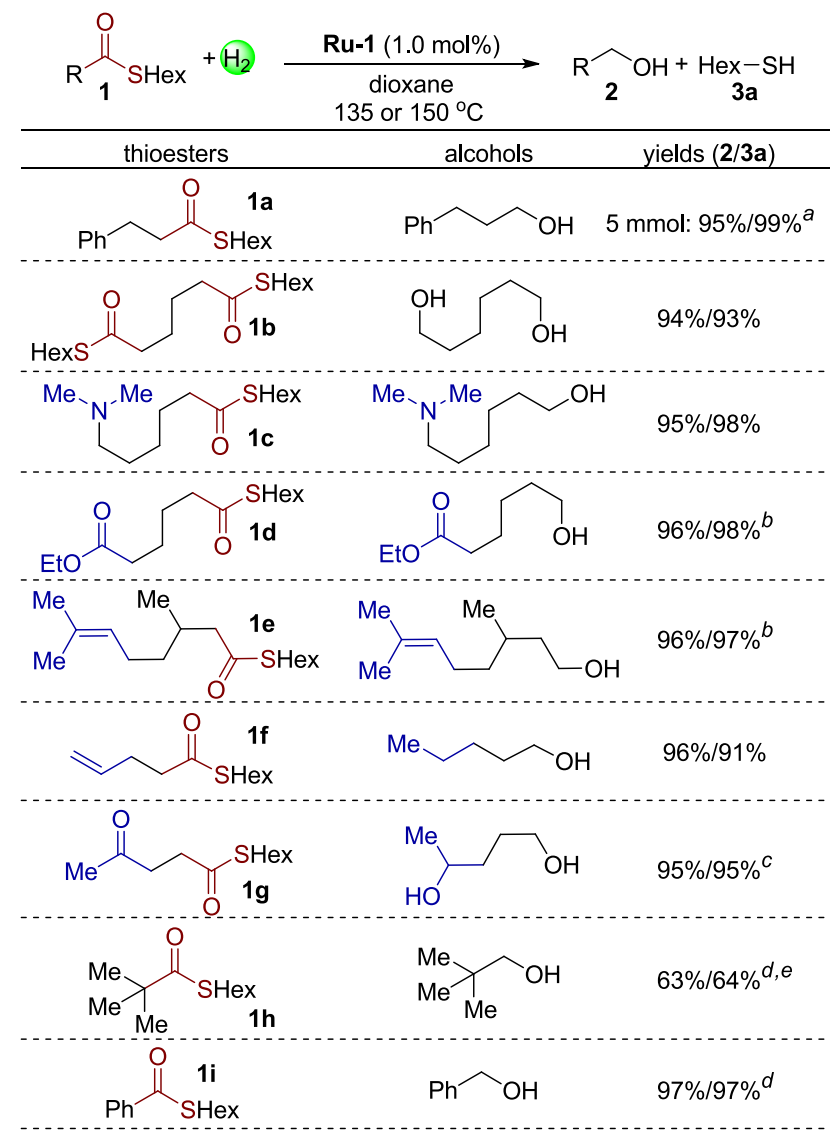

Conditions: substrate $(0.5 \mathrm{mmol})$, catalyst Ru-1 (1 mol\%), dioxane $(1 \mathrm{~mL}), 135^{\circ} \mathrm{C}, 20 \mathrm{bar} \mathrm{H}_{2}, 36 \mathrm{~h}$. Yields of products were determined by NMR and GC using benzyl benzoate or 1,3,5-trimethoxybenzene as internal standards; isolated yields in parentheses. Unless otherwise noted, the conversion of the reaction is $>99 \% .{ }^{a} \mathbf{1 a}(5 \mathrm{mmol}), \mathbf{R u}-\mathbf{1}$ (0.2 mol\%), dioxane $(3 \mathrm{~mL}), 150{ }^{\circ} \mathrm{C}, 30$ bar $\mathrm{H}_{2}, 2 \mathrm{~h} .{ }^{b} 150{ }^{\circ} \mathrm{C}$, in the presence of $2 \%$ hexanethiol. ${ }^{c}$ In the presence of 1 equiv of hexanethiol. ${ }^{d} 150{ }^{\circ} \mathrm{C}, 40$ bar $\mathrm{H}_{2} .{ }^{e} 66 \%$ conversion of $1 \mathbf{h}$.

95\% yield of the alcohol, and 99\% yield of hexanethiol). Subsequently, $S$-hexyl thioesters based on different acyl chains were studied at $0.5 \mathrm{mmol}$ scale under 20 bar $\mathrm{H}_{2}$ at $135{ }^{\circ} \mathrm{C}$ (Scheme 4). First, a bi-thioester compound $\mathbf{1 b}$ was successfully hydrogenated to 2 equiv of hexanethiol and hexanediol in 93\% and $94 \%$ yields, respectively. Additionally, a thioester with a tertiary amine group was also transformed to the corresponding products in excellent yields (1c). To our surprise, both ester and trisubstituted alkene groups remained untouched under the hydrogenation conditions, demonstrating the excellent selectivity of the system toward hydrogenation of thioester group (1d and 1e). In these two cases, $2 \%$ hexanethiol was added before the reaction to avoid the possible hydrogenation of the ester group or double bond by the first turnover of Ru-1. ${ }^{7 \mathrm{e}}$ However, functional groups more prone to hydrogenation, terminal alkenes and ketones for example, were hydrogenated simultaneously in the corresponding products ( $\mathbf{f}$ and $\mathbf{1 g}$ ). Even in the presence of 1 equiv of hexanethiol, the ketone group in $\mathbf{1 g}$ was fully hydrogenated. The reaction system appears sensitive to steric hindrance about the carbonyl group. For example, when thioester $\mathbf{1 h}$ with substantial steric hindrance was used as substrate, only $66 \%$ conversion of the thioester was achieved under $40 \mathrm{bar}_{2}$ at $150{ }^{\circ} \mathrm{C}$. Lastly, employing benzothioate 1i, excellent yields of benzyl alcohol and hexanethiol were obtained under 40 bar $\mathrm{H}_{2}$ at $150{ }^{\circ} \mathrm{C}$ ( $97 \%$ for both). Interestingly, upon addition of a catalytic amount of the Lewis acid $\operatorname{In}(\mathrm{OTf})_{3}$, hydrogenative deoxygenation of thioester $\mathbf{1 i}$ was achieved, resulting in formation of the corresponding sulfide in 90\% yield (see Supporting Information). ${ }^{14}$

Next, thioesters based on different thiols were explored (Scheme 5). Thioesters derived from longer thiol chains or

Scheme 5. Hydrogenation of Thioesters Based on Various Thiols

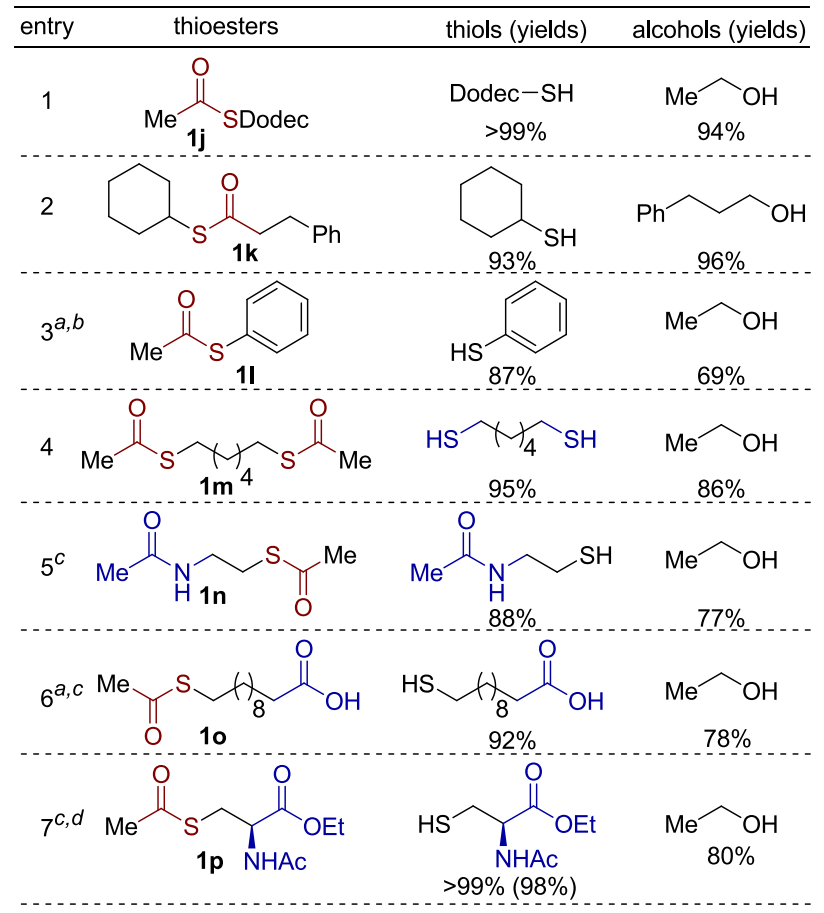

Conditions: Same as Scheme $4 .{ }^{a} 40$ bar $\mathrm{H}_{2} .{ }^{b}>90 \%$ conversion. ${ }^{c} 150$ ${ }^{\circ} \mathrm{C}$. ${ }^{d}$ In the presence of $2 \%$ hexanethiol.

secondary thiols were hydrogenated to the corresponding thiols and alcohols in excellent yields under the optimal conditions $(\mathbf{1 j}$ and $\mathbf{1 k})$. However, for thiophenol-based thioesters, 40 bar $\mathrm{H}_{2}$ was needed to ensure high conversion (>90\%), affording thiophenol in $87 \%$ yield (Scheme 5, entry 3). In addition, the dithiol-based thioester $1 \mathrm{~m}$ was fully hydrogenated (95\% yield of thiol). Similarly, functional groups on the thiol chain were examined. A tethered amide group was well tolerated under the reaction conditions, affording $N$-acetyl cysteamine in high yield (1n, 88\%). Surprisingly, the reaction system is also compatible with a carboxylic acid group. Employing the thioester 1o, the corresponding thio-substituted carboxylic acid was produced in $92 \%$ yield at $150{ }^{\circ} \mathrm{C}$ under 40 bar $\mathrm{H}_{2}$ in spite of the possible deactivation effect of the catalyst by the carboxylic acid group. ${ }^{15}$ Finally, the cysteine-derived thioester $1 p$ was also tested in the hydrogenation reaction (Scheme 5, entry 7). Satisfactorily, chiral $\mathrm{N}$-acetyl cysteine ethyl ester ${ }^{16}$ was obtained with excellent chemoselectivity 
toward the thioester unit. Noteworthy, no racemization of the chiral center was observed (see Supporting Information, pp S33-S34 and Figure S48). In contrast, base-catalyzed hydrolysis of $1 p$ does not only deprotect the ester group, but also causes elimination of the RS- group, forming olefinic side products. ${ }^{17}$ Significantly, this result indicates that the current system for selective hydrogenation of thioesters can serve as a deprotection strategy for the thiol group.

The success in efficient hydrogenation of thioesters and the tolerance toward the generated thiol motivated us to study other organosulfur compounds, which are also widely used and ubiquitous in natural products and pharmaceuticals. ${ }^{418}$ First, thiocarbamates were studied. To our surprise, all of the screened substrates were efficiently hydrogenated to the corresponding formamides and thiols, whereas in the case of the oxygen-based analogs, it is much harder to hydrogenate carbamates than amides and esters (Scheme 6, entries 1-

Scheme 6. Hydrogenation of Thiocarbamates and Thioamides

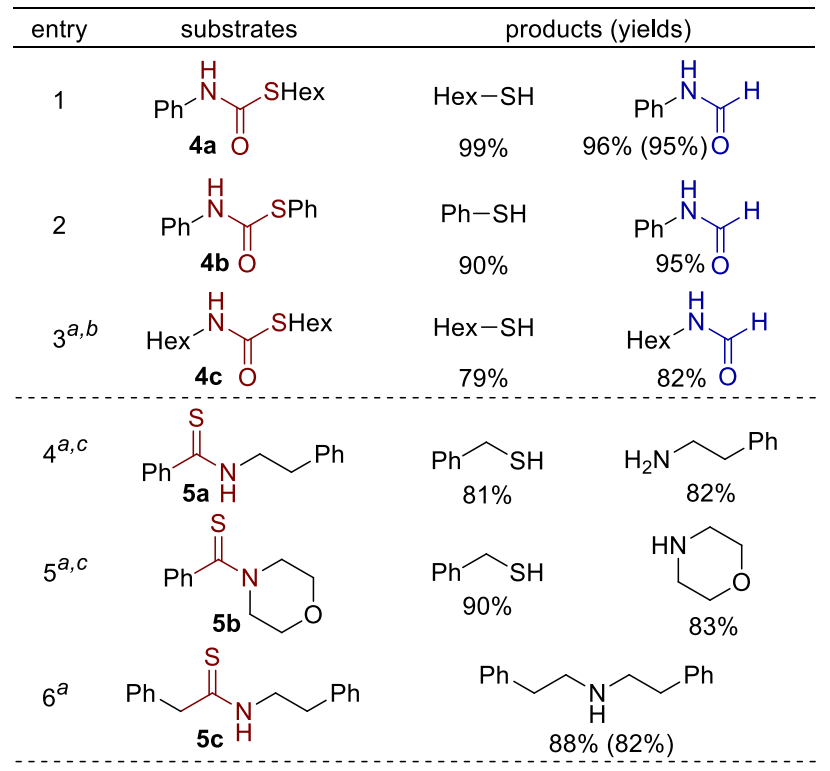

Conditions: Same as Scheme 4. ${ }^{a} 150{ }^{\circ} \mathrm{C}, 40$ bar $\mathrm{H}_{2} .{ }^{b}>80 \%$ conversion. ${ }^{c} \mathbf{R u}-1$ (1.5 mol\%).

3). ${ }^{5 e, 19}$ For thiocarbamate $4 \mathbf{c}$ with both alkyl chains attached to the $\mathrm{S}$ and $\mathrm{O}$ atoms, hydrogenation required higher temperature and pressure (entry $3,>80 \%$ conversion). We then turned our attention to organosulfur compounds containing a typical $\mathrm{C}=$ $S$ bond. ${ }^{20}$ Three different types of thioamides were tested (entries 4-6). While benzyl thiol and amines were generated as the major products starting from thioamides $\mathbf{5 a}$ and $\mathbf{5} \mathbf{b}$, most of thioamide $\mathbf{5 c}$ underwent hydrogenative desulfurization to afford the secondary amine ${ }^{21}$ in $88 \%$ yield. A possible reason for the observed chemoselectivity, i.e., cleavage of either $\mathrm{C}-\mathrm{N}$ or $\mathrm{C}-\mathrm{S}$ bond, is related to the stability of thioaldehyde intermediates. Specifically, thiobenzaldehyde is more stable than linear aliphatic thioaldehyde, which promotes its generation. Such chemoselectivity toward two types of products was also observed in the reduction of thioamides with amalgams ${ }^{22}$ (for proposed pathways and other unsuccessful examples, see the Supporting Information).

In conclusion, we have developed the unprecedented catalytic hydrogenation of thioesters to efficiently form thiols and alcohols, using a ruthenium acridine pincer complex as catalyst. Functional groups including amide, ester, carboxylic acid, and trisubstituted double bonds were tolerated, highlighting the excellent selectivity of the system. Since the catalyst is not deactivated by the generated thiol, the catalytic system was also utilized, for the first time, for the hydrogenation of thiocarbamates and thioamides, indicating a versatile range of applications. Other challenging reactions based on the developed system are being explored in our lab.

\section{ASSOCIATED CONTENT}

\section{SI Supporting Information}

The Supporting Information is available free of charge at https://pubs.acs.org/doi/10.1021/jacs.0c10884.

Experimental details, GC-MS/GC traces, characterization data, and NMR spectra (PDF)

\section{AUTHOR INFORMATION}

\section{Corresponding Author}

David Milstein - Department of Organic Chemistry, Weizmann Institute of Science, Rehovot 76100, Israel; (1) orcid.org/0000-0002-2320-0262;

Email: david.milstein@weizmann.ac.il

\section{Authors \\ Jie Luo - Department of Organic Chemistry, Weizmann Institute of Science, Rehovot 76100, Israel \\ Michael Rauch - Department of Organic Chemistry, Weizmann Institute of Science, Rehovot 76100, Israel \\ Liat Avram - Department of Chemical Research Support, Weizmann Institute of Science, Rehovot 76100, Israel; (1) orcid.org/0000-0001-6535-3470 \\ Yehoshoa Ben-David - Department of Organic Chemistry, Weizmann Institute of Science, Rehovot 76100, Israel}

Complete contact information is available at: https://pubs.acs.org/10.1021/jacs.0c10884

\section{Notes}

The authors declare no competing financial interest.

\section{ACKNOWLEDGMENTS}

This research was supported by the European Research Council (ERC AdG 692775). We thank Prof. Sergey Semenov and Dr. Yutao Sang for their help during the project. M.R. acknowledges the Zuckerman STEM Leadership Program for a research fellowship. D.M. is the Israel Matz Professorial Chair of Organic Chemistry.

\section{REFERENCES}

(1) (a) Mullowney, M. W.; McClure, R. A.; Robey, M. T.; Kelleher, N. L.; Thomson, R. J. Natural Products from Thioester Reductase Containing Biosynthetic Pathways. Nat. Prod. Rep. 2018, 35, 847878. (b) Read, J. A.; Walsh, C. T. The Lyngbyatoxin Biosynthetic Assembly Line: Chain Release by Four-Electron Reduction of a Dipeptidyl Thioester to the Corresponding Alcohol. J. Am. Chem. Soc. 2007, 129, 15762-15763. (c) Awodi, U. R.; Ronan, J. L.; Masschelein, J.; de los Santos, E. L. C.; Challis, G. L. Thioester Reduction and Aldehyde Transamination are Universal Steps in Actinobacterial Polyketide Alkaloid Biosynthesis. Chem. Sci. 2017, 8, 411-415.

(2) (a) Bobbio, P. A. Hydrogenolysis of Thioesters. J. Org. Chem. 1961, 26, 3023-3024. (b) Fukuyama, T.; Lin, S.-C.; Li, L. Facile Reduction of Ethyl Thiol Esters to Aldehydes: Application to a Total 
Synthesis of (+)-Neothramycin A Methyl Ether. J. Am. Chem. Soc. 1990, 112, 7050-7051.

(3) (a) Dawson, P. E.; Muir, T. W.; Clark-Lewis, l.; Kent, S. B. H. Synthesis of Proteins by Native Chemical Ligation. Science 1994, 266, 776-779. (b) Kanda, Y.; Ashizawa, T.; Kakita, S.; Takahashi, Y.; Kono, M.; Yoshida, M.; Saitoh, Y.; Okabe, M. Synthesis and Antitumor Activity of Novel Thioester Derivatives of Leinamycin. J. Med. Chem. 1999, 42, 1330-1332. (c) Martin, N.; Neelz, V.; Spinnler, H.-E. Suprathreshold Intensity and Odour Quality of Sulphides and Thioesters. Food Qual. Prefer. 2004, 15, 247-257. (d) Fujiwara, S.; Kambe, N. Thio-, Seleno-, and Telluro-Carboxylic Acid Esters. Top. Curr. Chem. 2005, 251, 87-140. (e) Pietrocola, F.; Galluzzi, L.; Bravo-San Pedro, J. M.; Madeo, F.; Kroemer, G. Acetyl Coenzyme A: A Central Metabolite and Second Messenger. Cell Metab. 2015, 21, 805-821. (f) Chandru, K.; Gilbert, A.; Butch, C.; Aono, M.; Cleaves, H. J. The Abiotic Chemistry of Thiolated Acetate Derivatives and the Origin of Life. Sci. Rep. 2016, 6, 29883-29892.

(4) (a) Wardell, J. L. In The Chemistry of Thiol Group; Patai, S., Ed.; John Wiley \& Sons: New York, 1974; p 230. (b) Cremlyn, R. J. An Introduction to Organosulfur Chemistry; John Wiley \& Sons: Chichester, 1996. (c) Hoyle, C. E.; Lowe, A. B.; Bowman, C. N. ThiolClick Chemistry: A Multifaceted Toolbox for Small Molecule and Polymer Synthesis. Chem. Soc. Rev. 2010, 39, 1355-1387. (d) Yin, C.; Huo, F.; Zhang, J.; Martínez-Máňez, R.; Yang, Y.; Lv, H.; Li, S. ThiolAddition Reactions and Their Applications in Thiol Recognition. Chem. Soc. Rev. 2013, 42, 6032-6059. (e) Poole, L. B. The Basics of Thiols and Cysteines in Redox Biology and Chemistry. Free Radical Biol. Med. 2015, 80, 148-157. (f) Dulsat-Serra, N.; Quintanilla-Casas, B.; Vichi, S. Volatile Thiols in Coffee: A Review on Their Formation, Degradation, Assessment and Influence on Coffee Sensory Quality. Food Res. Int. 2016, 89, 982-988.

(5) For selected reviews, see: (a) de Vries, J. G.; Elsevier, C. J. The Handbook of Homogeneous Hydrogenation with Bifunctional Ruthenium Catalysts; Wiley-VCH Verlag GmbH \& Co. KGaA, Weinheim, 2007. (b) Dub, P. A.; Ikariya, T. Catalytic Reductive Transformations of Carboxylic and Carbonic Acid Derivatives Using Molecular Hydrogen. ACS Catal. 2012, 2, 1718-1741. (c) Werkmeister, S.; Junge, K.; Beller, M. Catalytic Hydrogenation of Carboxylic Acid Esters, Amides, and Nitriles with Homogeneous Catalysts. Org. Process Res. Dev. 2014, 18, 289-302. (d) Ikariya, T.; Kayaki, Y. Hydrogenation of Carboxylic Acid Derivatives. Pure Appl. Chem. 2014, 86, 933-943. (e) Pritchard, J.; Filonenko, G. A.; van Putten, R.; Hensen, E. J. M.; Pidko, E. A. Heterogeneous and Homogeneous Catalysis for the Hydrogenation of Carboxylic Acid Derivatives: History, Advances and Future Directions. Chem. Soc. Rev. 2015, 44, 3808-3833. (f) Kallmeier, F.; Kempe, R. Manganese Complexes for (De)Hydrogenation Catalysis: A Comparison to Cobalt and Iron Catalysts. Angew. Chem., Int. Ed. 2018, 57, 46-60. (g) Filonenko, G. A.; van Putten, R.; Hensen, E. J. M.; Pidko, E. A. Catalytic (De)Hydrogenation Promoted by NonPrecious Metals-Co, Fe and $\mathrm{Mn}$ : Recent Advances in an Emerging Field. Chem. Soc. Rev. 2018, 47, 1459-1483.

(6) (a) Tamura, M.; Nakagawa, Y.; Tomishige, K. Recent Developments of Heterogeneous Catalysts for Hydrogenation of Carboxylic Acids to Their Corresponding Alcohols. Asian J. Org. Chem. 2020, 9, 126-143. (b) Geilen, F. M. A.; Engendahl, B.; Hölscher, M.; Klankermayer, J.; Leitner, W. Selective Homogeneous Hydrogenation of Biogenic Carboxylic Acids with $[\mathrm{Ru}(\text { TriPhos }) \mathrm{H}]^{+}$: A Mechanistic Study. J. Am. Chem. Soc. 2011, 133, 14349-14358. (c) Brewster, T. P.; Miller, A. J. M.; Heinekey, D. M.; Goldberg, K. I. Hydrogenation of Carboxylic Acids Catalyzed by Half-Sandwich Complexes of Iridium and Rhodium. J. Am. Chem. Soc. 2013, 135, 16022-16025. (d) Korstanje, T. J.; van der Vlugt, J. I.; Elsevier, C. J.; de Bruin, B. Hydrogenation of Carboxylic Acids with A Homogeneous Cobalt Catalyst. Science 2015, 350, 298-302.

(7) (a) Clarke, M. L. Recent Developments in the Homogeneous Hydrogenation of Carboxylic Acid Esters. Catal. Sci. Technol. 2012, 2, 2418-2423. (b) Sánchez, M. A.; Torres, G. C.; Mazzieri, V. A.; Pieck, C. L. Selective Hydrogenation of Fatty Acids and Methyl Esters of Fatty Acids to Obtain Fatty Alcohols-A Review. J. Chem. Technol.
Biotechnol. 2017, 92, 27-42. (c) Zhang, J.; Leitus, G.; Ben-David, Y.; Milstein, D. Efficient Homogeneous Catalytic Hydrogenation of Esters to Alcohols. Angew. Chem., Int. Ed. 2006, 45, 1113-1115. (d) Zell, T.; Ben-David, Y.; Milstein, D. Unprecedented IronCatalyzed Ester Hydrogenation. Mild, Selective, and Efficient Hydrogenation of Trifluoroacetic Esters to Alcohols Catalyzed by an Iron Pincer Complex. Angew. Chem., Int. Ed. 2014, 53, 4685-4689. (e) Zou, Y.-Q.; von Wolff, N.; Anaby, A.; Xie, Y.; Milstein, D. Ethylene Glycol as an Efficient and Reversible Liquid-Organic Hydrogen Carrier. Nat. Catal. 2019, 2, 415-422.

(8) (a) Smith, A. M.; Whyman, R. Review of Methods for the Catalytic Hydrogenation of Carboxamides. Chem. Rev. 2014, 114, 5477-5510. (b) Balaraman, E.; Gnanaprakasam, B.; Shimon, L. J. W.; Milstein, D. Direct Hydrogenation of Amides to Alcohols and Amines under Mild Conditions. J. Am. Chem. Soc. 2010, 132, 16756-16758. (c) Zou, Y.-Q.; Chakraborty, S.; Nerush, A.; Oren, D.; Diskin-Posner, Y.; Ben-David, Y.; Milstein, D. Highly Selective, Efficient Deoxygenative Hydrogenation of Amides Catalyzed by a Manganese Pincer Complex via Metal-Ligand Cooperation. ACS Catal. 2018, 8, 80148019. (d) Xie, Y.; Hu, P.; Bendikov, T.; Milstein, D. Heterogeneously Catalyzed Selective Hydrogenation of Amides to Alcohols and Amines. Catal. Sci. Technol. 2018, 8, 2784-2788.

(9) (a) Balaraman, E.; Ben-David, Y.; Milstein, D. Unprecedented Catalytic Hydrogenation of Urea Derivatives to Amines and Methanol. Angew. Chem., Int. Ed. 2011, 50, 11702-11705. (b) Balaraman, E.; Gunanathan, C.; Zhang, J.; Shimon, L. J. W.; Milstein, D. Efficient Hydrogenation of Organic Carbonates, Carbamates and Formates Indicates Alternative Routes to Methanol based on $\mathrm{CO}_{2}$ and CO. Nat. Chem. 2011, 3, 609-614. (c) Han, Z.; Rong, L.; Wu, J.; Zhang, L.; Wang, Z.; Ding, K. Catalytic Hydrogenation of Cyclic Carbonates: A Practical Approach from $\mathrm{CO}_{2}$ and Epoxides to Methanol and Diols. Angew. Chem., Int. Ed. 2012, 51, 13041-13045. (d) vom Stein, T.; Meuresch, M.; Limper, D.; Schmitz, M.; Hölscher, M.; Coetzee, J.; Cole-Hamilton, D. J.; Klankermayer, J.; Leitner, W. Highly Versatile Catalytic Hydrogenation of Carboxylic and Carbonic Acid Derivatives Using a Ru-Triphos Complex: Molecular Control over Selectivity and Substrate Scope. J. Am. Chem. Soc. 2014, 136, 13217-13225. (e) Das, U. K.; Kumar, A.; Ben-David, Y.; Iron, M. A.; Milstein, D. Manganese Catalyzed Hydrogenation of Carbamates and Urea Derivatives. J. Am. Chem. Soc. 2019, 141 (33), 12962-12966.

(10) For selected examples of hydrogenation-resistant thioester groups, see: (a) Kitamura, M.; Ohkuma, T.; Inoue, S.; Sayo, N.; Kumobayashi, H.; Akutagawa, S.; Ohta, T.; Takaya, H.; Noyori, R. Homogeneous Asymmetric Hydrogenation of Functionalized Ketones. J. Am. Chem. Soc. 1988, 110, 629-631. (b) Li, N.; Ou, J.; Miesch, M.; Chiu, P. Conjugate Reduction and Reductive Aldol Cyclization of $\alpha, \beta$-Unsaturated Thioesters Catalyzed by (BDP)CuH. Org. Biomol. Chem. 2011, 9, 6143-6147. (c) Iwasaki, K.; Wan, K. K.; Oppedisano, A.; Crossley, S. W. M.; Shenvi, R. A. Simple, Chemoselective Hydrogenation with Thermodynamic Stereocontrol. J. Am. Chem. Soc. 2014, 136, 1300-1303.

(11) (a) Luo, J.; Rauch, M.; Avram, L.; Diskin-Posner, Y.; Shmul, G.; Ben-David, Y.; Milstein, D. Formation of Thioesters by Dehydrogenative Coupling of Thiols and Alcohols with $\mathrm{H}_{2}$ Evolution. Nat. Catal. 2020, 3, 887-892. For flip of the acridine ring, see: (b) Ye, X.; Plessow, P. N.; Brinks, M. K.; Schelwies, M.; Schaub, T.; Rominger, F.; Paciello, R.; Limbach, M.; Hofmann, P. Alcohol Amination with Ammonia Catalyzed by an Acridine-Based Ruthenium Pincer Complex: A Mechanistic Study. J. Am. Chem. Soc. 2014, 136, 5923-5929. (c) Gellrich, U.; Khusnutdinova, J. R.; Leitus, G. M.; Milstein, D. Mechanistic Investigations of the Catalytic Formation of Lactams from Amines and Water with Liberation of $\mathrm{H}_{2}$. J. Am. Chem. Soc. 2015, 137, 4851-4859.

(12) Note that over time, the aldehyde further couples to form an ester in the absence of hydrogen gas.

(13) With other classical catalysts developed in our group (in the presence of catalytic amount of base), the reaction could indeed generate some products; however, the conversion was inadequate 
( $<35 \%)$, possibly due to poisoning of the catalyst by the generated thiol.

(14) $\operatorname{In}(\mathrm{OTf})_{3}$ and Ru-1-catalyzed oxidation of alkenes by water: Tang, S.; Ben-David, Y.; Milstein, D. Oxidation of Alkenes by Water with $\mathrm{H}_{2}$ Liberation. J. Am. Chem. Soc. 2020, 142, 5980-5984.

(15) Balaraman, E.; Khaskin, E.; Leitus, G.; Milstein, D. Catalytic Transformation of Alcohols to Carboxylic Acid Salts and $\mathrm{H}_{2}$ Using Water as the Oxygen Atom Source. Nat. Chem. 2013, 5, 122-125.

(16) Giustarini, D.; Milzani, A.; Dalle-Donne, I.; Tsikas, D.; Rossi, R. N-Acetylcysteine Ethyl Ester (NACET): A Novel Lipophilic CellPermeable Cysteine Derivative with an Unusual Pharmacokinetic Feature and Remarkable Antioxidant Potential. Biochem. Pharmacol. 2012, 84, 1522-1533.

(17) (a) Greene, T. W. Protection for the Thiol Group; Wuts, P. G. M., Ed.; John Wiley \& Sons: Hoboken, NJ, 2014; pp 837-894. (b) Hiskey, R. G.; Upham, R. A.; Beverly, G. M.; Jones, W. C. SulfurContaining Polypeptides. X. $\beta$-Elimination of Mercaptides from Cysteine Peptides. J. Org. Chem. 1970, 35, 513-515.

(18) (a) Chen, Y. S.; Schuphan, I.; Casida, J. E. S-Chloroallyl Thiocarbamate Herbicides: Mouse Hepatic Microsomal Oxygenase and Rat Metabolism of cis- and trans- $\left[{ }^{14} \mathrm{C}=\mathrm{O}\right]$ Diallate. J. Agric. Food Chem. 1979, 27, 709-712. (b) Murai, T. Chemistry of Thioamides; Springer Nature Singapore Pte Ltd., 2019.

(19) The ease of hydrogenation of benzoyl-type thiocarbamates might originate from their thermo-stability under the reaction conditions; see: (a) Delebecq, E.; Pascault, J.-P.; Boutevin, B.; Ganachaud, F. On the Versatility of Urethane/Urea Bonds: Reversibility, Blocked Isocyanate, and Non-isocyanate Polyurethane. Chem. Rev. 2013, 113, 80-118. (b) Li, L.; Chen, X.; Torkelson, J. M. Reprocessable Polymer Networks via Thiourethane Dynamic Chemistry: Recovery of Cross-link Density after Recycling and Proof-of-Principle Solvolysis Leading to Monomer Recovery. Macromolecules 2019, 52, 8207-8216.

(20) Wiberg, K. B.; Wang, Y. A Comparison of Some Properties of C $=\mathrm{O}$ and $\mathrm{C}=\mathrm{S}$ Bonds. ARKIVOC 2011, 2011, 45-56.

(21) Wünsch, B.; Geiger, C. Reduction of Carbonic and Carboxylic Acid Derivatives. Science of Synthesis 2009, 40, 23-64.

(22) In the reduction of thiobenzamide with sodium amalgam, thiobenzaldehdye was observed as the major product. See amalgam reduction part of the following: (a) Hurd, R. N.; DeLaMater, G. The Preparation and Chemical Properties of Thionamides. Chem. Rev. 1961, 61, 45-86. Selected references about the stabilities of thioaldehydes: (b) Vedejs, E.; Perry, D. A. 2,2-Dimethylpropanethial: A Long-Lived Aliphatic Thioaldehyde. J. Am. Chem. Soc. 1983, 105, 1683-1684. (c) Becher, J.; Jørgensen, P. L.; Frydendahl, H.; FältHansen, B. A Facile Preparation of o-Aminoheteroarenecarbothialdehydes. Synthesis 1991, 1991, 609-612. (d) Okazaki, R. Kinetic Stabilization of Highly Reactive Species Bearing Heteroatoms. Heteroat. Chem. 2014, 25, 293-305. 